\title{
Effects of Partial Body Weight Support while Training Acute Stroke Patients to Walk Backwards on a Treadmill -A Controlled Clinical Trial Using Randomized Allocation-
}

\author{
AKIYOSHI TAKAMI, RPT, PhD $^{1)}$, SAICHI WAKAYAMA, RPT ${ }^{2)}$ \\ ${ }^{1)}$ Department of Strokology and Rehabilitation, Research Institute for Brain and Blood \\ Vessels-Akita: 6-10 Sensyukubota-machi, Akita 010-0874, Japan. \\ TEL: +81 18-833-0115, FAX: +81 18-833-2104,E-mail: takami@akita-noken.jp \\ ${ }^{2)}$ Hirosaki University Graduate School of Health Sciences
}

\begin{abstract}
Purpose] We tested the efficacy of an intervention training acute stroke patients to walk backwards on a treadmill. Subjects were randomly allocated to three groups of Partial Body Weight Support treadmill backward walking group, Partial Body Weight Support treadmill forward walking group and Control in order to compare the efficacy of the interventions among the groups. [Subjects] The subjects were 36 acute stroke patients. [Methods] They were randomly allocated to the three groups using an envelope method. After 3 weeks of intervention. We investigated by multiple comparisons among the three groups using change scores for each of the outcome measures. [Results] The Berg Balance Scale showed no significant differences. The Rivermead Mobility Index showed a significant difference between the backward walking group and the forward walking group, and between the backward walking group and the Control. Walking speed was significantly different between the backward walking group and the Control. No differences were seen for other itemes. [Conclusions] As a result of 3-week intervention, a significant improvement was observed in walking speed and the Rivermead Mobility Index, suggesting that Partial Body Weight Support treadmill backward walking training for patients in the early phase of acute stroke is effective at improving mobility.
\end{abstract}

Key words: Acute stroke, BWSTT, Backward walk

(This article was submitted Nov. 30, 2009, and was accepted Jan. 12, 2010)

\section{INTRODUCTION}

The aim of this study was to clarify the effect of backward walking training for acute stroke patients. Walking backwards is different from walking forwards as toe contact is made at the initial foot contact during the stance phase of the gait cycle and the leg is swung, while conscious of the hip extensors' position, in the swing phase. Moreover, differences in muscle activity patterns and myogenic potentials occur while walking backwards compared to walking forwards ${ }^{1-4)}$. For this reason, walking backwards can lead to effects that are not produced by walking forwards as well as increasing exercise tolerance $e^{2,3,5,6)}$.

Training patients to walk backwards may be used as a therapeutic intervention to improve mobility in stroke patients. In a randomized, controlled trial, Yang et al. ${ }^{7)}$ reported improvement in walking speed or cadence among stroke patients who were trained to walk backwards. Weng et al. ${ }^{8)}$ showed that gait function and balance were improved using 
a treadmill to train subjects to walk backwards. However, because walking backwards involves a high risk of falls, only stroke patients in the chronic phase with a quasi-stable gait should undergo this type of training. For walking forwards, partial body weight support (BWS) training has been performed as a therapeutic intervention using a treadmill for patients lacking a fully stable gait in the early stage of rehabilitation, and is purportedly effectiveness ${ }^{9,10)}$; provided that there are reports to the effect that a training has an effect and those to the effect that any effect can hardly be expected in a systematic review ${ }^{11,12)}$. One report showed no significant difference between this training and conventional training, particularly in acute-phase stroke rehabilitation ${ }^{13,14)}$. The effect of interventions using partial BWS treadmill training has not been established. In addition, there are no reports comparing training subjects to walk backwards versus forwards on a treadmill with partial BWS. This randomized, controlled study examined the effect of a therapeutic intervention using backward treadmill walking training with reduced load, using partial BWS to ensure safety, for acute stroke patients with unstable gait. Furthermore, forward and backward walking were compared in terms of ability to improve motor capacity.

\section{SUBJECTS AND METHODS}

\section{Subjects}

Acute stroke patients who were hospitalized between April 2009 and July 2009, and underwent physical therapy at the Research Institute for Brain and Blood Vessels-AKITA (Japan) were enrolled. Of 82 patients receiving physical therapy, 36 met the following inclusion criteria: (1) success walking 10 meters using braces or canes ; (2) post-stroke period less than 5 weeks; (3)Functional Independence Measure-Locomotion ${ }^{15)}$ score of 5 or lower; and (4) perfect scores on the Berg Balance Scale ${ }^{16)}$ and the Rivermead Mobility Index ${ }^{17)}$, both of which are main outcome measures described below. Patients with a time of 4 seconds or less to cover $10-\mathrm{m}$ at maximum walking speed were excluded, as were patients with factors interfering with training or tests, including those with uncontrolled health conditions, parkinsonism, severe communication disorders, dementia, and orthopedic and other gait-influencing diseases.
This study was approved by the Ethics Committee of the Research Institute for Brain and Blood Vessels-AKITA. All patients provided their informed consent after receiving a written description of the purpose and details of the study.

\section{Methods}

Subjects: The 36 patients who participated were allocated to groups of three patients when they were able to walk for 10 meters. Subsequently, they were randomly allocated to one of following three groups using an envelope method: partial BWS treadmill backward walking group (BWS-B) $(\mathrm{n}=12)$, partial body weight support treadmill forward walking group (BWS-F) $(\mathrm{n}=12)$, and a control group $(\mathrm{n}=$ 12). Two patients in the BWS-B and one in the BWS-F group dropped out during the 3-week intervention for family reasons. All patients in the control group completed the study. Thus, the completion rate was $91.7 \%$.

Intervention: For BWS treadmill training, the intervention consisted of 30 minutes of conventional training and 10 minutes of treadmill training walking either backwards or forwards, depending on the group. This 40-minute total training period was performed 6 times a week for 3 weeks. In addition to strengthening, stretching, proprioceptive neuromuscular facilitation, function and mobility activities, and other training activities, Conventional training consisted of overground training of walking $150-200 \mathrm{~m}$ based on the distance covered in the treadmill intervention. The control group underwent 40 minutes of conventional training 6 times a week for 3 weeks. In addition, a 40-minute Activities of Daily Living (ADL) exercise was conducted 5 times a week. Ergometer cycling, treadmill walking without body weight support, walking 200 or more meters without a rest, climbing the stairs three floors or more at a time, and other motor tasks requiring 3 or more consecutive minutes were prohibited.

For BWS treadmill training, exercise tolerance was set based on several reports $9,10,13,14,18-20)$. Because walking backwards is a difficult task, we started with a low load, increasing the speed and time as the experiment progressed. During Week 1, the intervention was performed at $0.8 \mathrm{~km} / \mathrm{h}$ for 3 minutes, separated by a 4-minute rest, and performed again for 3 minutes. During Week 2, the intervention was performed at a speed of $1.0 \mathrm{~km} / \mathrm{h}$ for 4 minutes, separated by a 3 -minute rest, and 
performed again for 4 minutes. During Week 3, the intervention was performed at a speed of $1.3 \mathrm{~km} / \mathrm{h}$ for 4 minutes, separated by a 3 -minute rest, and performed again for 4 minutes. Weight reduction was set at $30 \%$ of the weight of each patient throughout the study. The angle was set at $0^{\circ}$, allowing use of the safety bar.

Training stops and cardiovascular monitoring. Treadmill walking and other interventions were stopped if any of the following criteria were met: systolic blood pressure $>200 \mathrm{mmHg}$ and diastolic blood pressure $>110 \mathrm{mmHg}$ for ischemic stroke patients and systolic blood pressure $>160 \mathrm{mmHg}$ and diastolic blood pressure $>110 \mathrm{mmHg}$ for intracerebral hemorrhage patients. In addition, an intervention was terminated if mean blood pressure increased by $30 \mathrm{mmHg}$ or decreased by $20 \mathrm{~mm} \mathrm{Hg}$ during an intervention. For heart rate, an intervention was terminated if heart rate was $>110$ beats $/ \mathrm{min}$ at rest or increased $30 \%$ during an intervention. In addition, an intervention was stopped if $\mathrm{SPO}_{2}$ was $<90 \%$, breathing rate was $>30$ breaths $/ \mathrm{min}$, or the modified Borg scale ${ }^{21)}$, score was $>7$.

Main outcome measures. Five outcomes measures were used: (1) the Berg Balance Scale; (2) the Rivermead Mobility Index; (3) the 10-m maximum walking speed; (4) the walk ratio during $10 \mathrm{~m}$ of forward walking; and (5) the walk ratio during $5 \mathrm{~m}$ of backwards walking. These five main outcome measures were measured once a week before and during the 3-week intervention The Berg Balance Scale was used to assess balance ${ }^{16)}$. The Berg Balance Scale is known for its reliability, validity, and good sensitivity for stroke patients $^{22,23)}$. The Rivermead Mobility Index was used to assess mobility ${ }^{17)}$. The Rivermead Mobility Index is applicable to other mobility indices and its reliability is well-established too ${ }^{24,25)}$. The $10-\mathrm{m}$ maximum walking speed was measured as follows: A $15-\mathrm{m}$ walking route was prepared that had a $2.5-\mathrm{m}$ section at each end of the route; these $2.5-\mathrm{m}$ sections were considered the "runways". A physical therapist measured the required time and number of steps to walk the $10 \mathrm{~m}$ between the runways. Step-length, step-rate, and walk-ratio were obtained from these measured values. The walk-ratio during $10 \mathrm{~m}$ of comfortable forward walking was obtained under the same conditions as those for measuring maximum walking speed. Finally, the walk-ratio during a 5-m backward walk (comfortable walking speed) was measured ${ }^{26}$. For this test, a 10-m walking route was prepared, and a physical therapist measured the required time and number of steps needed to walk $5 \mathrm{~m}$ backwards. Step-length, step-rate, and walk-ratio were obtained from these measured values. Because backward walking is not a standard intervention, patients were instructed to practice it several times in advance and to walk at the speed at which they felt safe. Each measurement was performed once for each subject using a stopwatch. To prevent patients from deviating from the walking route, vertical lines were provided to guide patients over the walking routes. Height corrections were made for steplength and step-rate ${ }^{27}$, as follows:

Step-length correction $=$ step-length $\times($ Height $/$ Mean height $)^{-1}$

Step-rate correction $=$ step-rate $\times($ Height $/$ Mean height $)^{0.5}$

Corrected walking speed and walk ratios were determined using these equations.

Secondary outcomes were The Motricity Index ${ }^{28)}$, which represents the degree of motor paralysis, and the Functional Independence Measure-Locomotion tool ${ }^{15)}$, which assesses motor disability. Furthermore, the number of steps on the treadmill over a 30 -second period was measured once a week in the two groups undergoing treadmill training, allowing the calculation of the predicted distance of step-length.

The measurements of main outcome measures, step-rate in treadmill walking, overground maximum walking speed and forward and backward comfortable walking speed were performed on the same day; the results of the modified Borg Scale were recorded simultaneously.

Data analysis: The Berg Balance Scale, Rivermead Mobility Index, maximum walking speed, step-length, step-rate, walk-ratio, and Motricity Index were analyzed preliminarily using Shapiro-Wilk's test for normality and a homoscedastic test (Levine's test) for equality of variance. Normality was confirmed for each index. Accordingly, analysis of variance was performed to compare clinical characteristics and results among the three groups before the intervention began. Variables compared included age, height, weight, days post-stroke, and scores on the Berg Balance Scale, Rivermead Mobility Index, maximum walking speed, step-length, step-rate, walk-ratio, and Motricity Index. In terms of gender, hemiplegic side, and diagnosis, the $\chi^{2}$ test was 
Table 1-1. Baseline demographic and clinical characteristics of the intervention Groups and Control group

\begin{tabular}{lccc}
\hline & BWS-Backward group $^{\mathrm{a}}$ & BWS-Forward group $^{\mathrm{b}}$ & Control group $^{\mathrm{c}}$ \\
\hline Variables & & & \\
Age (y) & $66.1 \pm 6.3$ & $71.1 \pm 10.6$ & $66.9 \pm 10.6$ \\
Height (cm) & $159.3 \pm 8.4$ & $159.3 \pm 8.3$ & $158.1 \pm 7.4$ \\
Weight (kg) & $54.7 \pm 10.3$ & $61.0 \pm 14.8$ & $57.8 \pm 8.5$ \\
Days post stroke & $13.2 \pm 8.4$ & $14.7 \pm 8.1$ & $13.7 \pm 8.9$ \\
Gender (Woman) & 6 & 3 & 7 \\
Hemiplegics side (Right) & 7 & 5 & 10 \\
Diagnosis (ischemic stroke) & 7 & 11 & 11 \\
Motricity Index (L/E) $^{\mathrm{d}}$ & $77.7 \pm 16.6$ & $77.3 \pm 18.4$ & $68.2 \pm 17.0$ \\
\hline
\end{tabular}

Mean \pm standard deviation, $* \mathrm{p}<0.05, * * \mathrm{p}<0.01$ by ANOVA and $\chi^{2}$ test

${ }^{a}$ BWS-Backward: partial body weight support backward walk treadmill training group

${ }^{b}$ BWS-Backward: partial body weight support forward walk treadmill training group

${ }^{\mathrm{c} C o n t r o l: ~ o v e r ~ g r o u n d ~ w a l k ~ t r a i n i n g ~ g r o u p ~}$

${ }^{\mathrm{d}}$ Motricity Index of lower extremity.

Table 1-2. Baseline demographic and clinical characteristics of the intervention Groups and Control group

\begin{tabular}{lccc}
\hline & BWS-Backward group & BWS-Forward group & Control group \\
\hline Variables & & & \\
BBS (0-56) & $43.2 \pm 8.9$ & $42.7 \pm 10.8$ & $41.7 \pm 8.1$ \\
RMI (0-15) & $7.1 \pm 1.8$ & $7.2 \pm 2.3$ & $6.3 \pm 1.3$ \\
Gait variables & & & \\
$\quad$ Velocity (m/min) & $59.3 \pm 29.4$ & $63.7 \pm 39.0$ & $56.2 \pm 27.0$ \\
Cadence (steps/min) & $116.4 \pm 43.1$ & $131.1 \pm 49.0$ & $124.2 \pm 40.9$ \\
Step length (m) & $0.48 \pm 0.13$ & $0.44 \pm 0.17$ & $0.43 \pm 0.11$ \\
Comfortable walk-ratio (m/steps/min) & & & \\
$\quad$ Forward walk-ratio & $0.005 \pm 0.002$ & $0.004 \pm 0.001$ & $0.004 \pm 0.001$ \\
Backward walk-ratio & $0.002 \pm 0.001$ & $0.002 \pm 0.001$ & $0.002 \pm 0.001$ \\
\hline
\end{tabular}

Mean \pm standard deviation, ${ }^{*} \mathrm{p}<0.05,{ }^{*} \mathrm{p}<0.01$ by ANOVA with Tukey HSD multiple comparisons test.

performed to compare groups. A paired $t$-test was used to compare between the main outcome measures before and after the intervention, and the Tukey HSD method was used for multiple comparison tests to determine any differences among the BWS-B, BWS-F, and control groups.

The modified Borg Scale and the number of steps were assessed using the Mann-Whitney test and non-paired $t$-test, respectively, in comparisons between the BWS-B and BWS-F groups. A paired $t$-test was used for comparisons of overground comfortable walking, step-length prediction on a treadmill, and cadence. A significance level of $\mathrm{p}<$ 0.05 was used for each test. SPSS16 for Windows was used for statistical analysis.

\section{RESULTS}

The baseline demographics and clinical characteristics of the three groups are shown in Table 1. There were no significant differences in any of these variables among the groups. According to a report by Jørgensen, patients recover roughly $80 \%$ from neurologic symptoms within 4.5 weeks of stroke onset ${ }^{29}$. The mean height was $158.9 \mathrm{~cm}$, and this value was used to calculate the corrected values which were used for calculating each parameter of walking. Values for the main outcome measures before the intervention period are also shown in Table 1. No statistically significant difference was observed among the groups for any primary outcome measure before the intervention. In addition, no item showed a 
Table 2. Main Outcome Measures of the intervention groups and Control group

\begin{tabular}{lccccrr}
\hline & \multicolumn{2}{c}{ BWS-Backward group $(\mathrm{n}=10)$} & \multicolumn{2}{c}{ BWS-Forward group $(\mathrm{n}=11)$} & \multicolumn{2}{c}{ Control group (n=12) } \\
\hline Variables & \multicolumn{1}{c}{ Pretest } & Posttest & Pretest & Posttest & \multicolumn{1}{c}{ Pretest } & Posttest \\
\hline BBS (0-56) & $43.2 \pm 8.9$ & $54.8 \pm 2.4^{* *}$ & $42.7 \pm 10.8$ & $50.6 \pm 5.6^{* *}$ & $41.7 \pm 8.1$ & $48.1 \pm 9.2^{* *}$ \\
RMI (0-15) & $7.1 \pm 1.8$ & $11.9 \pm 2.1^{* *}$ & $7.2 \pm 2.3$ & $9.6 \pm 3.4^{* *}$ & $6.3 \pm 1.3$ & $8.4 \pm 2.9^{* *}$ \\
Gait variables & & & & & & \\
Velocity (m/min) & $59.3 \pm 29.4$ & $91.5 \pm 23.3^{* *}$ & $63.7 \pm 39.0$ & $84.8 \pm 30.2^{* *}$ & $56.2 \pm 27.0$ & $66.8 \pm 29.4$ \\
Cadence (steps/min) & $116.4 \pm 43.1$ & $157.3 \pm 19.4^{*}$ & $131.1 \pm 49.0$ & $148.8 \pm 34.9^{*}$ & $124.2 \pm 40.9$ & $137.3 \pm 40.4$ \\
Step length (m) & $0.48 \pm 0.13$ & $0.59 \pm 0.14^{* *}$ & $0.44 \pm 0.17$ & $0.56 \pm 0.10^{* *}$ & $0.43 \pm 0.11$ & $0.47 \pm 0.12$ \\
\hline
\end{tabular}

Mean \pm standard deviation, ${ }^{*} \mathrm{p}<0.05,{ }^{*} * \mathrm{p}<0.01$ by paired $t$-test.

Table 3. Change scores of the Main Outcome Measures of the intervention groups and Control group

\begin{tabular}{lccc}
\hline & BWS-Backward group & BWS-Forward group & Control group \\
\hline Variables & $\begin{array}{c}(\mathrm{n}=10) \\
\text { Change score }\end{array}$ & $\begin{array}{c}(\mathrm{n}=11) \\
\text { Change score }\end{array}$ & $\begin{array}{c}(\mathrm{n}=12) \\
\text { Change score }\end{array}$ \\
\hline BBS (0-56) & $12.6 \pm 8.5$ & $8.8 \pm 7.0$ & $6.4 \pm 7.1$ \\
RMI (0-15) & $5.2 \pm 2.0$ & $2.7 \pm 2.3$ & $1.8 \pm 2.4^{* *}$ \\
Gait variables & & & \\
Velocity (m/min) & $35.7 \pm 22.5$ & $25.2 \pm 21.7$ & $7.9 \pm 1.9^{*}$ \\
Cadence (steps/min) & $45.7 \pm 49.7$ & $31.4 \pm 22.7$ & $12.6 \pm 23.6$ \\
Step length $(\mathrm{m})$ & $0.13 \pm 0.08$ & $0.12 \pm 0.10$ & $0.03 \pm 0.08^{*}$ \\
\hline
\end{tabular}

Mean \pm standard deviation

${ }^{*} \mathrm{p}<0.05,{ }^{* *} \mathrm{p}<0.01$ by ANOVA with Tukey HSD multiple comparisons test.

significant difference in any post hoc comparison (data not shown).

Values for each item on the Berg Balance Scale, Rivermead Mobility Index and maximum walking speed before and after the intervention are shown in Table 2. The Berg Balance Scale showed a significant improvement in all three groups . Similarly, the Rivermead Mobility Index showed a significant improvement in all three groups . A significant improvement in $10-\mathrm{m}$ maximum walking speed was observed in the BWS-B and BWS-F groups compared to the control group. An improvement in maximum walking speed was observed in the control group from before to after the intervention, but it was not statistically significant

The results of multiple comparisons among the three groups of changes in scores from before the intervention to after the intervention for the Berg Balance Scale, the Rivermead Mobility Index, and maximum walking speed are shown in Table 3 . The Berg Balance Scale score was highest in the BWSB group, with post-test scores of $54.8 \pm 2.4$ and changes in scores of $12.6 \pm 8.5$, but here were no significant differences among the groups. There was a significant difference in changes in scores between the BWS-B and BWS-F groups in the Rivermead Mobility Index (5.2 \pm 2.0 vs $2.7 \pm 2.3$, respectively; $p=0.047$ ). In addition, a significant difference was also observed between the BWS-B and BWS-F groups and the control group $(1.8 \pm 2.4$; $\mathrm{p}=0.006$ ). Maximum walking speed showed the greatest improvement in the BWS-B group. Multiple comparisons showed a significant difference between the BWS-B and control group (p $=0.018$ ) for maximum walking speed, but no significant difference between the BWS-B and BWS-F groups. There was also no difference between the other groups .

The walk-ratio during a comfortable walk is approximately $0.006 \mathrm{~m} / \mathrm{step} / \mathrm{min}$ in healthy adults ${ }^{30,31)}$. Because both high and low values indicate low efficiency, comparisons among the three groups were based on values obtained at the completion of intervention instead of change scores (Table 4). The walk ratio during forward walking 
Table 4. Walk-ratio end of training score of the intervention groups and Control group

\begin{tabular}{lccc}
\hline & BWS-Backward group & BWS-Forward group & Control group \\
\hline Variables & Score & Score & Score \\
\hline Comfortable walking & & & \\
Forward walk-ratio(m/steps/min) & $0.0044 \pm 0.0003$ & $0.0044 \pm 0.0007$ & $0.0038 \pm 0.0006^{*}$ \\
$\quad$ Cadence (steps/min) & $114.3 \pm 21.1$ & $110.3 \pm 25.3$ & $104.1 \pm 26.1$ \\
step-length (m) & $0.50 \pm 0.11$ & $0.47 \pm 0.08$ & $0.39 \pm 0.09^{*}$ \\
Backward walk-ratio (m/steps/min) & $0.0026 \pm 0.0005$ & $0.0021 \pm 0.0008$ & $0.0017 \pm 0.0008$ \\
Cadence (steps/min) & $108.9 \pm 21.6$ & $122.1 \pm 36.8$ & $89.1 \pm 31.3$ \\
step-length (m) & $0.28 \pm 0.08$ & $0.24 \pm 0.08$ & $0.16 \pm 0.09^{*}$ \\
\hline
\end{tabular}

Mean \pm standard deviation, ${ }^{*} \mathrm{p}<0.05,{ }^{* *} \mathrm{p}<0.01$ by ANOVA with Tukey HSD multiple comparisons test.

Table 5. Modified Borg scale scores for BWS-Backward and BWS-Forward treadmill training

\begin{tabular}{lcc}
\hline & BWS-Backward group & BWS-Forward group \\
\hline Variables & Borg score & Borg score \\
\hline BWS treadmill training & & \\
1 week $(0.8 \mathrm{~km} / \mathrm{h})$ & $2.0(0-4)$ & $1.0(0-4)$ \\
2 week $(1.0 \mathrm{~km} / \mathrm{h})$ & $2.0(0-3)$ & $0.5(0-4)$ \\
3 week $(1.3 \mathrm{~km} / \mathrm{h})$ & $3.0(0-4)$ & $3.0(0-4)$ \\
\hline
\end{tabular}

Median (maximum-minimum), ${ }^{*} \mathrm{p}<0.05,{ }^{*} \mathrm{p}<0.01$ by Mann-Whitney test.

Table 6. Number of steps for a comparison of BWS-Backward and BWSForward treadmill training

\begin{tabular}{ccc}
\hline Variables & $\begin{array}{c}\text { BWS-Backward group } \\
\text { Steps }\end{array}$ & $\begin{array}{c}\text { BWS-Forward group } \\
\text { Steps }\end{array}$ \\
\hline BWS treadmill training & & \\
1 week $(0.8 \mathrm{~km} / \mathrm{h})$ & $40.5 \pm 13.6$ & $39.0 \pm 14.0$ \\
2 week $(1.0 \mathrm{~km} / \mathrm{h})$ & $37.6 \pm 13.8$ & $42.8 \pm 7.0$ \\
3 week $(1.3 \mathrm{~km} / \mathrm{h})$ & $48.3 \pm 11.5$ & $45.9 \pm 9.3$ \\
\hline
\end{tabular}

Mean \pm standard deviation, ${ }^{*} \mathrm{p}<0.05,{ }^{*} \mathrm{p}<0.01$ by non paired $t$-test.

showed a significant difference between the BWS$\mathrm{B}$ and control groups with the former groups being slightly closer to $0.006 \mathrm{~m} / \mathrm{step} / \mathrm{min}$. There were no differences in walk ratio or backward walking (over ground) among the groups.

No patient required training be stopped during the study. Results of comparisons of the Borg scale for each week between the BWS-B and BWS-F groups are shown in Table 5. The values ranged from 0 to 4 at the maximum for every load for both groups. Although the median score at the treadmill speed of $1.3 \mathrm{~km} / \mathrm{h}$ was 3.0 , no patient had a score indicating a particularly strong rating of perceived exertion. Values were slightly higher in the BWS-B group than the BWS-F group at weeks 1 and 2, but the differences were not statistically significant.

The mean number of steps for 30 seconds during BWS treadmill training is shown in Table 6. There was no significant difference between the BWS-B and BWS-F groups with both groups showing about 40 steps. The mean number of steps was low in the BWS-B group, particularly at $1.0 \mathrm{~km} / \mathrm{h}, 37.6 \pm 13.8$ and $42.8 \pm 7.0$ steps in the BWS-B and BWS-F groups, respectively, but the differences were not 
Table 7. Step-lengths for a comparison of over ground comfortable walking and treadmill training walking

\begin{tabular}{lcccc}
\hline & \multicolumn{2}{c}{ BWS-Backward group } & \multicolumn{2}{c}{ BWS-Forward group } \\
\hline $\begin{array}{l}\text { Variables } \\
\text { step-length }(\mathrm{m})\end{array}$ & $\begin{array}{r}\text { over ground } \\
\text { step-length }(\mathrm{m})\end{array}$ & over ground & treadmill \\
\hline BWS treadmill training & & & & \\
1 week $(0.8 \mathrm{~km} / \mathrm{h})$ & $0.22 \pm 0.11$ & $0.19 \pm 0.08$ & $0.37 \pm 0.14$ & $0.20 \pm 0.03^{* *}$ \\
2 week $(1.0 \mathrm{~km} / \mathrm{h})$ & $0.27 \pm 0.08$ & $0.24 \pm 0.09$ & $0.43 \pm 0.13$ & $0.19 \pm 0.03^{* *}$ \\
3 week $(1.3 \mathrm{~km} / \mathrm{h})$ & $0.28 \pm 0.11$ & $0.25 \pm 0.07$ & $0.45 \pm 0.12$ & $0.25 \pm 0.04^{* *}$ \\
\hline
\end{tabular}

Mean \pm standard deviation, ${ }^{*} \mathrm{p}<0.05,{ }^{*} \mathrm{p}<0.01$ by paired $t$-test.

Table 8. Cadence of comfortable over ground backward walking and BWSBackward treadmill training

\begin{tabular}{lcc}
\hline & over ground backward walk & BWS-Backward treadmill \\
\hline Variables & steps $/$ min & steps $/$ min \\
\hline BWS treadmill training & & \\
1 week $(0.8 \mathrm{~km} / \mathrm{h})$ & $108.2 \pm 21.2$ & $76.2 \pm 27.9^{*}$ \\
2 week $(1.0 \mathrm{~km} / \mathrm{h})$ & $101.9 \pm 24.2$ & $80.0 \pm 26.1$ \\
3 week $(1.3 \mathrm{~km} / \mathrm{h})$ & $107.9 \pm 22.9$ & $98.7 \pm 26.9$ \\
\hline
\end{tabular}

Mean \pm standard deviation, ${ }^{*} \mathrm{p}<0.05,{ }^{*} \mathrm{p}<0.01$ by non paired $t$-test.

significant.

A comparative study was performed for steplength during over-ground comfortable walking and on the treadmill for forward and backward walking. The predicted step-length on the treadmill was obtained using the predicted walking distance for 30 seconds at the designated speed and the number of steps. The results of the comparison by exercise intensity are shown in Table 7. In the BWS-B group, step-length during over-ground walking and treadmill walking ranged from $0.22-0.25 \mathrm{~m}$, with no significant differences between types of walking. In contrast, there was a significant difference in step-length during over-ground walking and treadmill walking in the BWS-F group, with a steplength on the treadmill of approximately half of that of over-ground walking. The results of the comparison of cadence between over-ground comfortable backward walking and backward treadmill walking are shown in Table 8. There was a significant difference between over-ground walking and treadmill walking at week 1 at $0.8 \mathrm{~km} /$ h $(108.2 \pm 21.2 \mathrm{step} / \mathrm{min}$ vs $76.2 \pm 27.9 \mathrm{step} / \mathrm{min}$, respectively). There were no significant differences at week $2(1.0 \mathrm{~km} / \mathrm{h})$ or week $3(1.3 \mathrm{~km} / \mathrm{h})$ between backward treadmill walking and backward over- ground walking.

\section{DISCUSSION}

We examined the effect of three training interventions on stroke patients within 5 weeks after the onset of illness to determine which intervention was the most effective.

Except for walking speed in the control group, all three intervention groups showed a significant improvement in the Berg Balance Scale, the Rivermead Mobility Index, and maximum walking speed after 3 weeks of intervention. Natural recovery is a characteristic of acute stroke patients $^{29)}$. However, when it comes to changes in scores for these variables, there were different trends between the three groups for the Rivermead Mobility Index and maximum walking speed, suggesting an effect of BWS-B on various parameters. The effect of training is important to the ability to function in daily life. The Rivermead Mobility Index showed a significantly greater improvement in the BWS-B group than the BWS-F and control groups after the 3 -week intervention, while there was no significant differences between the BWS-F and control groups (Table 3). These 
results indicate that BWS-B training allows for earlier transfer to activities of daily living than BWS-F or conventional training. In addition, the BWS-B group showed a significant improvement in walking speed compared to the control group. Though no significant difference in walking speed was observed between the BWS-B and BWS-F groups, a tendency of improved walking speed was noted in the BWS-B group. There was no difference between the BWS-F and control groups in improvement of walking speed. We speculate that BWS-B training is more effective at restoring mobility than conventional training.

The Berg Balance Scale, which measures balance performance, showed a higher value in the BWS-B group in terms of both the score obtained after the intervention and the change score than in the other two groups, although differences between groups were not significant. There may have been a ceiling effect, a feature of the Berg Balance Scale, based on the finding that final scores in the BWS-B group were $54.8 \pm 2.4$, which is very close to a perfect score, and, in fact, several patients have been shown to have perfect scores on this scale in other studies $^{24)}$.

Overall, BWS-B training was considered effective for early improvement of mobility activities in stroke patients, because BWS-B training lead to an improvement in several different parameters. The reason for the positive effects of BWS-B treadmill training may be related to the fact that this type of training uses a task-oriented approach and is in accordance with the motor learning theory ${ }^{24)}$. Our findings are considered consistent with a report by Nudo et al. showing that constraint-movement of the hemiplegic side leg facilitates its recovery, wherein securing a series of multiple steps ${ }^{32}$. There is activation of a central pattern generator in a neurophysiological mechanism, although this has not been well established for stroke. An experiment performed by Dietz et al. ${ }^{33)}$ with partial body weight also demonstrated that there was a walk-like muscular activity on the hemiplegic side leg in patients with spinal cord injury. This was confirmed by a report by Calancie et al. ${ }^{34)}$ This central nervous system effect was explained by Dimitrijevic et al. ${ }^{35}$ ) who described a mechanism in which myogenic potential is periodically applied to the flexors muscles and extensor muscles of the lower limb, presumably observed at the L2 level in humans, and by Kautz et al. ${ }^{36)}$ and Fujiwara ${ }^{37)}$ who described the use of pedal training to treat strokes. A central pattern generator is a system in which the rhythmic alternate contraction of flexor muscles and extensor muscles, as occurs in walking, is generated in the spinal cord ${ }^{38)}$. According to these reports, the spinal cord central pattern generator system is activated by a concentric signal, and this may have potential for the treatment of strokes. Though backward walking is not necessarily the same as forward walking in the gait cycle, there are many similarities ${ }^{39)}$ and without doubt alternate contraction of flexor muscles and extensor muscles of the lower extremities are generated. As a result, BWS-B training may permit adequate distribution of concentric signals to the central pattern generator by actuating a cyclic step from the early stage, as seen in forward walking.

While BWS treadmill training is superior to pedal training because it is performed in an upright position, BWS-F is normally superior due to the use of a forward walking posture. Nonetheless, although no significant differences between BWS-F and control intervention in acute stroke patients have been shown in other studies ${ }^{13,14)}$, our results showed the efficacy of BWS-B, or backward walking. Two systematic reviews contain evidence that undergoing a certain amount of training improves walking competence in stroke patients ${ }^{11,40)}$. If a certain amount of exercise time is given, a training task that makes lower extremity muscles discharge myogenic potential in a given time is generally effective. It is reported that discharged myogenic potential capacity is higher at various sites in backward walking than in forward walking ${ }^{1-4)}$. Both forward and backward treadmill training were performed over the same period of time and with the same exercise tolerance in this study. We speculate that backward walking is superior at raising the exercise intensity of muscle activities owing to high energy consumption even in a short period of time.

The results of this study also showed that the numbers of steps in both forward and backward treadmill walking were almost the same, that is, approximately 40 steps in 30 seconds. Because this test was performed with the same exercise tolerance, the resulting step-length and step rate were almost the same in forward and backward treadmill walking. In general, unlike in forward walking, making the step-length shorter in 
backward walking allows for an increased step rate $^{1,41)}$. This trend is noticeable particularly in elderly people and acute stroke patients ${ }^{42}$. Our findings showed that patients undergoing the training intervention had the same step-length and step rate in both forward and backward treadmill walking with partial weight, suggesting the possibility that exercise tolerance is different for treadmill walking than for over-ground walking. In fact, a comparison with comfortable over-ground walking demonstrated that step-length was significantly shorter in over-ground walking than in forward treadmill walking. Meanwhile, step-length in backward walking was almost the same in treadmill walking and over-ground walking. Moreover, the results of a comparison of walking rate between comfortable backward walking and treadmill backward walking revealed a significantly lower rate for treadmill backward walking at 0.8 $\mathrm{km} / \mathrm{h}$ as well as lower exercise tolerance. It is generally said that the step rate is higher and stride is lower in treadmill walking than in over-ground walking ${ }^{43,44)}$. This is one of the problems of the transferal of forward treadmill walking to overground walking. The BWS-B training performed in this study showed a pattern different from that described in reports on studies of forward walking, indicating that a walking style with a relatively reduced step rate is adopted without significantly reducing step-length. This may result from the fact that a patient holds his body in suspension to have a higher level of security and engages in activities on the same spot, holding hand rails, when on the treadmill. Backward ground walking does not permit visual compensation for retropulsion in stroke patients, who are thus prone to experiencing fear of a falling ${ }^{42)}$. However, a patient stays on the same spot in the treadmill walking to perform the exercise, and even if he fails, he merely slides forward, presumably allowing walking with a slightly longer step-length than in over-ground backward walking. In addition, patient were not conscious of the imposition of higher exercise tolerance than in forward walking as shown by the modified Borg scale. We believe that BWS-B exercise tolerance training, which is performed in a specific manner, leads to additional benefits compared to BSW-F and contributed to increased step-length in forward walking.

The additional benefits of BWS-B exercise tolerance training were considered have to lead to the slightly better results for the walking ratio than those seen in the control group. The walking ratio in forward walking is said to be $0.006 \mathrm{~m} / \mathrm{steps} / \mathrm{min}$ in healthy adults and $0.005 \mathrm{~m} / \mathrm{steps} / \mathrm{min}$ in elderly subjects $^{30,31)}$. It has been suggested that step-length is reduced and the walk ratio is increased with age, and that acute stroke patients show similar trends ${ }^{42}$. A constant walk ratio represents adequate energy costs during walking. A trend of modest improvement in step-length was observed in this study, probably resulting in more optimized energy costs than seen with conventional training. Nonetheless, the step-length was lower than that obtained before the intervention, or $0.005 \mathrm{step} / \mathrm{min} /$ $\mathrm{m}$, and did not significantly improve over time. Consequently, optimization of energy costs during comfortable walking was not likely to have been attained. No significant differences were observed in the walking ratios of over-ground backward walking after the intervention. We speculate that BWS-B training is not necessarily connected to backward walking.

No significant differences were observed between the BWS-F and control groups for most parameters. It is not clear if this finding is the result of spontaneous remission among our stroke patients. According to Pohl et al., values are improved by setting an appropriate exercise tolerance in treadmill training ${ }^{20)}$. The low exercise tolerance used for BWS-B training might be inappropriate for forward walking. Future studies are needed to confirm this hypothesis.

Study Limitations: It is difficult to judge the degree of exercise tolerance, the amount of reduced weight-bearing, speed, time period, and angle in BWS treadmill training, regardless of forward or backward walking. Though this comparative study was controlled for backward walking, it is not known if our adjustments were adequate. Because the time from stroke onset to intervention was short (mean, $13.8 \pm 8.3$ days), the duration of treadmill training was set at 10 minutes to reduce risks. This short period represents roughly $25 \%$ of all. Thus, we need to consider whether any real effect was obtained through the partial intervention used. Future studies are necessary to study to evaluate the best time period after stroke in which to begin the training program. In addition, our small sample size makes it difficult to generalize our findings to a larger population. Moreover, exercise therapy for stroke, the long-term effects in the short run even if 
there are many reports that there is no change. Thus, long-term follow-up is necessary.

In Conclusions, after a 3-week intervention, a significant improvement was observed in walking speed and the Rivermead Mobility Index with BWS-B compared to other interventions. The parameters that improved are important for mobility in activities of daily living. Our findings suggest that BWS-B training performed by patients in the early phase of an acute stroke may be effective at improving mobility early on in the recovery process.

\section{REFERENCES}

1) Chen LY, Su FC, Chiang PY: Kinematic and EMG analysis of backward walking on treadmill. Engineering in Medicine and Biology Society, 2000, 2: 825-827.

2) Grasso R, Bianchi L, Lacquaniti F: Motor patterns for human gait: backward versus forward locomotion. J Neurophysiol, 1998, 80: 1868-1885.

3) Cipriani DJ, Armstrong CW, Gaul S: Backward walking at three levels of treadmill inclination: an electromyographic and kinematic analysis. J Orthop Sports Phys Ther, 1995, 22: 95-102.

4) Masumoto $\mathrm{K}$, Takasugi $\mathrm{S}$, Hotta $\mathrm{N}$, et al.: A comparison of muscle activity and heart rate response during backward and forward walking on an underwater treadmill. Gait Posture, 2007, 25: 222228.

5) Dufek JS: Exercise variability, a prescription for overuse injury prevention. Health Fit J, 2002, 6: 618623.

6) Davies PM: Right in the middle: selective trunk activity in the treatment of adult hemiplegia. Heidelberg: Springer-Verlag, 1990.

7) Yang YR, Yen JG, Wang RY, et al.: Gait outcomes after additional backward walking training in patients with stroke: a randomized controlled trial. Clin Rehabil, 2005, 19: 264-273.

8) Weng CS, Wang J, Pan XY, et al.: Effectiveness of backward walking treadmill training in lower extremity function after stroke. Zhonghua Yi Xue Za Zhi, 2006, 86: 2635-2638.

9) Laufer Y, Dickstein R, Chefez Y, et al.: The effect of treadmill training on the ambulation of stroke survivors in the early stages of rehabilition: a randomized study. J Rehabil Res Dev, 2001, 38: 6978.

10) Franceschini $M$, Carda $S$, Agosti $M$, et al.: Walking after stroke: what dose treadmill training with body weight support add to overground gait training in patients early after stroke? Stroke, 2009, 40: 30793085.

11) Van Peppen RP, Kwakkel G, Wood-Dauphinee S, et al.: The impact of physical therapy on functional outcomes after stroke: what's the evidence? Clin Rehabil, 2004, 18: 833-826.

12) Teasell RW, Bhogal SK, Foley NC, et al.: Gait retraining post stroke. Tpo Stroke Rehabil, 2003, 10: 34-65.

13) da Cunha IT Jr, Lim PA, Qureshy H, et al.: Gait outcomes after aute stroke rehabilition with support treadmill ambulation training: a randomized controlled pilot sutdy. Arch Phys Med Rehabil, 2002, 83: 12581265.

14) Nilsson L, Carlsson J, Daniel A, et al.: Walking training of patients with hemiparesis at an early stage after stroke: a comparison of walking training on a treadmill with body weight support and walking training on the ground. Clin Rehabil, 2001, 15: 515527.

15) Data Management service of the Uniform Data System for Medical Rehabilitation and the Center for Functional Assessment Research: Guide for use of the uniform data set for medical rehabiliation. version3.0, State University of New York at Buffalo, 1990.

16) Berg KO, Wodd-Dauphinee S, Williams JI, et al.: Measuring balance in the elderly: preliminary development of an instrument. Physiother Can, 1989, 41: 304-311.

17) Collen FM, Wade DT, Robb GF, et al.: The Rivermead Mobility Index: a further development of the Rivermead Motor Asessment. Int Disabil Stud, 1991, 13: 50-54.

18) Visintin M, Barbeau H, Korner-Bitensky N, et al.: A new approach to retrain gait in stroke patients through body weight support and treadmill stimulation. Stroke, 1998, 29: 1122-1128.

19) Hesse S, Bertelt C, Jahnke MT, et al.: Teadmill training with partial body weight support compared with physiotherapy in nonambulatory hemiparatic patients. Stroke, 1995, 26: 976-981.

20) Pohl M, Mehrholz J, Ritschel C, et al.: Speeddependent treadmill training in ambulatory hemiparetic stroke patients: a randomized controlled trial.Stroke, 2002, 33: 553-558.

21) Borg GA: Psychophysical bases of perceived exertion. Med Sci Sports Exerc, 1982; 14: 377-381.

22) Berg KO: Measuring balance in the elderly: development and validation of an instrument [dissertation]. Montreal: McGill Univercity, 1992.

23) Shumway-Cook A, Baldwin M, Polissar NL, et al.: Predicting the probability for fall in communitydwelling older adults. Phys Ther, 1997, 77: 812-819.

24) Shumway-Cook A, Woollacott MH: Motor ControlTheory and Practical Applications(2nd ed). Philadelphia: Lippincott Williams \& Wilkins, 2001.

25) Forlander DA, Bohannon RW: Rivermead Mobility Index: a brief review of research to date. Clin Rehabil, 1999, 13: 97-100.

26) Salbach MN, Mayo NE, Higgins J, et al.: Responsiveness and predictability of gait speed and 
other disability measures in acute stroke. Arch Phys Med Rehabil, 2001, 82: 1204-1212.

27) Furuna T, Nagasaki H: Motor abilities of older adults in Japanese urban and rural communities. J Phys Fitness Sports Med, 1995, 44: 347-356.

28) Demeurisse G, DEmol O, Robaye E: Motor evaluation in vascular hemiplegia. Euro Neurol, 1980, 19: 382389.

29) Jørgensen HS, Nakayama H, Raaschou HO, et al.: Outcome and time course of recovery in stroke.Part II: Time course recovery. The Copenhagen Stroke Study. Arch Phys Med Rehabil, 1995, 76: 406-412.

30) Nagasaki H, Itoh $H$, Hashizume $K$, et al.: Walking patterns and finger rhythm of older adults. Percept Mot Skills, 1996, 82: 435-447.

31) Sekiya N, Nagasaki H: Reprodecibility of the walking patterns of normal young adults: test-retest reliability of walk ratio(steplength/step-rate). Gait Posture, 1998, 7: 225-227.

32) Nudo RJ, Wise BM, SiFuentes F, et al.: Neural substrates for the effects of rehabilitative training on motor recovery after ischemic infarct. Science, 1996, 272: 1791-1794.

33) Dietz VA, Colmbo G, Jensen L: Locomotor activity in spinal man. Lancet, 1994, 344: 1260-1263.

34) Calancie B, Needham-Shropshire B, Jacobs P, et al.: Involuntary stepping after chronic spinal cord injury. Evidence for a central rhythm generator for locomotion in man. Brain, 1994, 117: 1143-1159.

35) Dimitrijevic MR, Gerasimenko Y, Pinter MM: Evidence for a spinal central pattern generator in humans. Ann NY Acad Sci, 1998, 860: 360-376.

36) Kautz SA, Patten C, Neptune RR: Dose unilateral pedaling activate a rhythmic locomotor pattern in the nonpedaling leg in post-stroke hemiparesis? J Neurophysiol, 2006, 95: 3154-3163.

37) Fujiwara T, Liu M, Tanuma A, et al.: Pedaling exercise for neuromuscular re-education: a review. Crit Rev Phys Rehabil Med, 2005, 17: 163-177.

38) Grillner S, Wallén P: Central pattern generators for locomotion, with special reference to vertebrates. Ann Rev Neurosci, 1985, 8: 233-261.

39) Vilensky JA, Gankiewicz E, Gehlsen G: A kinematic comparison of backward and forward walking in humans. J Hum Mov Studies, 1987, 13: 29-50.

40) Kwakkel G, van Peppen R, Wagenaar RC, et al.: Effects of augmented exercise therapy time after stroke: a meta-analysis. Stroke, 2004, 35: 2529-2539.

41) Laufer Y: Age-and gender-related changes in the temporal-spatial characteristics of forwards and backwards gaits. Physiother Res Int, 2003, 8: 131-142.

42) Takami A, Wakayama S: Characteristics of backward walking in acute stroke patient: compare forward walking with backward walking. Tohoku rigaku ryohogaku, 2009, 21: 104-110(in Japanese).

43) Strathy GM, Chao EY, Laughman RK: Changes in knee function associated with treadmill ambulation. Biomechanics, 1983, 16: 517-522.

44) Murray MP, Spurr GB, Sepic SB, et al.: Treadmill vs. floor walking: kinematics, electromyogram, and heart rate. J Appl Physiol, 1985, 52: 87-91. 